\title{
Comparison of body mass index values proposed by Cole et al. (2000) and Must et al. (1991) for identifying obese children with weight-for-height index recommended by the World Health Organization
}

\author{
Marcelo Militão Abrantes ${ }^{1}$, Joel Alves Lamounier ${ }^{2, *}$ and Enrico Antônio Colosimo ${ }^{3}$ \\ ${ }^{1}$ Military Police Hospital of Minas Gerais (HPM-MG), Brazil: '²Department of Pediatrics, School of Medicine, \\ Federal University of Minas Gerais, Av. Alfredo Balena 190, Belo Horizonte, MG, Brazil, CEP 30130-100: \\ ${ }^{3}$ Department of Statistics, Federal University of Minas Gerais, Brazil
}

Submitted 16 April 2002: Accepted 9 October 2002

\begin{abstract}
Objectives: To calculate the sensitivity, specificity and agreement of body mass index (BMI) values proposed by Cole et al. (Br. Med.J. 2000; 320: 1) and Must et al. (Am.J. Clin. Nutr. 1991; 53: 839 \& 54: 773) with weight-for-height index in the nutritional evaluation of children.

Design: Criterion standards for diagnostic tests.

Setting: North-east and south-east Brazil.

Subjects: Two thousand nine hundred and twenty children studied in Life Pattern Research performed by the Brazilian Institute of Geography and Statistics in 1997. Main outcome measures are the sensitivity, specificity and agreement of BMI values proposed by Must et al. (1991) and Cole et al. (2000).

Results: Sensitivity of values proposed by both authors was around 90\%. Specificity was almost 100\% considering weight-for-height index as the gold standard. The agreement of both values with weight-for-height index, based on kappa results, was good and in pre-school children it was excellent.

Conclusions: Values proposed by Cole et al. (2000) and Must et al. (1991) should be used carefully to screen obesity in childhood but can be used to 'diagnose' overweight children with a very low chance of having false-positive results. Although the values proposed by both authors performed similarly, use of Cole et al.'s values should be encouraged. The latter cover children from 2 to 6 years old; their values are presented for six-month age intervals; they are based on a larger sample from six different countries; and they are related to the definition of adult obesity.
\end{abstract}

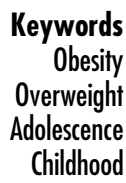

Keywords

Overweight

Childhood
Obesity is considered a global epidemic by the World Health Organization (WHO) ${ }^{1}$. Anthropometry, based on weight and height measures, is one of the methods used most frequently to identify people at higher risk of nutrition disorders, obesity included ${ }^{1}$

The likelihood of nutritional disorders can be diagnosed by comparing an anthropometric index to reference values $^{2}$. Anthropometric indices are calculated from the combination of at least two basic measures: weight, height/stature, sex and age ${ }^{2}$. Nowadays, body mass index (BMI) is the index used most often to screen obesity. It is calculated with the formula: weight (in $\mathrm{kg}$ ) divided by height (in metres) squared, and was developed by Lambert Adolphe Jacques Quetelet, a Belgian mathematician, in the 19th century ${ }^{3}$. This index has been widely accepted and used in adult anthropometry, with the highest and lowest limits of normality being based on statistical criteria relating to the higher mortality of people having BMI higher or lower than these values ${ }^{1,4-6}$.

The use of BMI for the nutritional evaluation of children and adolescents became more common after Must et al. published their reference data in $1991^{7,8}$. They are considered reference values by WHO to screen overweight and obesity among adolescents ${ }^{1}$. Since then, new percentile curves for children and adolescents have been proposed by several authors ${ }^{9-16}$ and have been used to screen obesity among children, although WHO recommends the use of weight-for-height index at this age ${ }^{1}$.

Recently there has been a tendency to use statistical criteria and continuity for adult BMI values to define obesity and overweight in childhood and adolescence $^{1,4,10,12,16-18}$. This is important because obesity definition in adulthood is based on statistical criteria of morbidity and mortality and '... [since] there is little frank 
disease during adolescence, it is particularly important to consider the degree to which adolescent anthropometry may predict risk factors or disease in adulthood' ${ }^{1}$. In 2000, Cole et al. $^{16}$ (under the auspices of the International Obesity Task Force (IOTF)) proposed BMI cut-off values pointing out this actual tendency.

The use of these different criteria (BMI cut-off values) makes comparison of prevalences more difficult ${ }^{4}$ and the problem of establishing consensual criteria for the upper limit of normality in children and adolescents has been cited: 'development of a consensus measure of childhood obesity has been limited by the lack of data on the validity of the BMI as a measure of adiposity; the absence of a reference population for the assessment of obesity in other populations; lack of agreement on which cutoff point to use; and few studies have examined the sensitivity, specificity, and predictive value of the persistence of obesity or the development of its complications $^{18}$. Some comparison of different BMI values has been already done, but with different statistical methods than the ones employed in the present work ${ }^{19,20}$.

The objective of this paper is to analyse the sensitivity, specificity and agreement of BMI values proposed as limits defining overweight and obesity by Cole et al. (IOTF) ${ }^{16}$ and Must et al. ${ }^{7,8}$ with weight-for-height index in the nutritional evaluation of children.

\section{Methodology}

The data used in this study were taken from the CD-ROM data of Life Pattern Research, a study carried out by the Brazilian Institute of Geography and Statistics supported by the World Bank. Interviews and questionnaires, completed by families selected randomly from the north and south regions of Brazil, evaluated living conditions, demographic tendencies (migration, fecundity, birth aspects), access to education and health, nutrition and anthropometry $^{21}$.

This sample was composed of 19409 adults and children living in 5000 households, distributed in 554 census areas in the north-east and south-east of Brazil. The sample was selected through two steps: the first was a proportional selection of geographical units based on the Demographic Census of 1991, and the second was a random selection based on housing type ${ }^{21}$.

From this database all of the 3786 children (up to 10 years old) were considered, but since no weight or height information was available for 252 of them, they were not included in this analysis. Among those 3534 remaining, 614 were less than 24 months old and were not analysed since Cole et al. (IOTF) ${ }^{16}$ proposed BMI values only for children aged 2 years or older, making comparison with younger children impossible. Therefore the data of 2920 children were used in the present study. The upper age limit of 10 years was chosen because WHO recommends the use of weight-for-height index to identify obese children only (and BMI for identification of obese adolescents).

The weight and height values and sex were taken from the main database and stored in Epi Info, version $6.04^{22}$. BMI was calculated with the formula: weight/(height $)^{2}$. Age was calculated in months as the difference between the date of the examination and the child's birth date.

Epi Info calculated the $Z$-score of weight-for-height index for each child according to the National Center for Health Statistics (NCHS) reference values ${ }^{22}$. Obese children were considered to be those with a $Z$-score greater than two standard deviations $(>2 S D)$ from the NCHS reference ${ }^{1}$.

Two programs were developed based on Epi Info to classify the nutritional status of children according to the values of Must et $a l^{7,8}$ and Cole et al. (IOTF) ${ }^{16}$ after grouping them by age and sex. In the first, children with BMI values lower than the proposed limits for overweight by each author were considered to be 'eutrophic', and children with BMI values equal to or greater than the proposed limit for overweight were considered as 'overweight'. The second program used the values proposed as limits for obesity by each author in the same way as the first program to classify children and 'obese'.

So, for each child, five different nutritional classifications were made: one according to weight-for-height index, two according to BMI values proposed as the limit for overweight by Cole et al. (IOTF) ${ }^{16}$ and Must et al. ${ }^{7,8}$, and another two according to BMI values proposed by both authors as the limit for obesity. In each of them children were classified as 'eutrophic' or 'overweight/obese'.

To compare these different nutritional classifications, children were sorted into classic age group definitions: pre-school children ( 2 years to 6 years and 11 months old) and schoolchildren ( 7 years to 9 years and 11 months old). Since Must et al. ${ }^{7,8}$ proposed values only for children aged 6 years or older, the calculations involving this reference were performed only for schoolchildren (7-10 years old).

The classifications were compared by four $2 \times 2$ tables. In each one, children were distributed in the vertical columns by their nutritional classification (eutrophic or overweight/obese) according to weight-for-height index. In the horizontal lines, children were distributed according to values proposed as limits for overweight by Must et al.$^{7,8}$ and Cole et al. (IOTF) ${ }^{16}$ (two tables - one for each author) and obesity (another two tables - one for each author).

Considering weight-for-height index as the gold standard, the sensitivity and specificity of the values proposed as limits for overweight and obesity by the two authors were calculated.

The kappa index was also calculated to measure the agreement between the nutritional classifications by BMI values proposed as limits for overweight and obesity by Cole et al. (IOTF) ${ }^{16}$ and Must et al. ${ }^{7,8}$ and weight-forheight index. This method is used when there is no gold standard. A value of zero means no concordance 
and a value of unity means perfect concordance. The more the concordance, the higher the kappa value: values less than 0.40 are considered as weak concordance, values between 0.40 and 0.75 as reasonable or good concordance and values higher than 0.75 as excellent concordance ${ }^{23,24}$.

\section{Results}

Of the 2920 children studied, 1744 (59.7\%) were preschool children and 1176 (40.3\%) were schoolchildren. The sex distribution was 1456 (49.9\%) males and 1464 (50.1\%) females. The mean age was 71.6 months and the median age was 73 months.

The prevalence of obesity classified by weight-forheight index is presented in Table 1.

The sensitivity of BMI values proposed as limits for overweight and obesity by Cole et al. (IOTF) ${ }^{16}$ and Must et $a l^{7,8}$, compared with weight-for-height index for schoolchildren, is presented in Table 2 . The specificity of these values is presented in Table 3 .

Agreement between nutritional classifications by BMI values proposed as limits for overweight by Cole et al. (IOTF) ${ }^{16}$ and Must et al..$^{7,8}$ and weight-for-height index, measured by the kappa index, is presented in Table 4 for school-age children.

The sensitivity, specificity and agreement of BMI values proposed as limits for overweight and obesity by Cole et al. $(\text { IOTF })^{16}$, compared with weight-for-height index, are presented in Table 5 for pre-school children.

\section{Discussion}

In the nutritional evaluation of children, WHO recommends the use of weight-for-height index with $Z$-score

Table 1 Obesity prevalence (\%) classified by weight-for-height index and Z-score $>2$ SD as cut-off point

\begin{tabular}{lrrrrrrrr}
\hline & \multicolumn{2}{c}{ Males } & & \multicolumn{2}{c}{ Females } & & \multicolumn{2}{c}{ Both } \\
\cline { 2 - 3 } Age (years) & \multicolumn{1}{c}{$\%$} & \multicolumn{1}{c}{$n$} & & $\%$ & \multicolumn{1}{c}{$n$} & & $\%$ & $n$ \\
\hline $2-7$ & 9.5 & 861 & & 10.8 & 883 & & 10.1 & 1744 \\
$7-10$ & 13.6 & 595 & & 21.5 & 581 & & 17.5 & 1176 \\
$2-10$ & 11.2 & 1456 & & 15.0 & 1464 & & 13.1 & 2920 \\
\hline
\end{tabular}

SD - standard deviation; \% - prevalence of obesity; $n$ - number of children analysed (sample).

Table 2 Sensitivity (\%) of BMI values proposed as limits for overweight and obesity by Cole et al. (IOTF) ${ }^{16}$ and Must et al. ${ }^{7,8}$, compared with weight-for-height index and Z-score $>2 S D$ as cut-off point, for schoolchildren

\begin{tabular}{|c|c|c|c|c|c|c|}
\hline & \multicolumn{2}{|c|}{ Males } & \multicolumn{2}{|c|}{ Females } & \multicolumn{2}{|c|}{ Both } \\
\hline & Cole & Must & Cole & Must & Cole & Must \\
\hline $\begin{array}{l}\text { Overweight } \\
\text { Obesity }\end{array}$ & $\begin{array}{l}80.2 \\
34.6\end{array}$ & $\begin{array}{l}81.6 \\
58.6\end{array}$ & $\begin{array}{l}49.6 \\
23.2\end{array}$ & $\begin{array}{l}51.5 \\
33.3\end{array}$ & $\begin{array}{l}61.7 \\
27.6\end{array}$ & $\begin{array}{l}63.5 \\
43.4\end{array}$ \\
\hline
\end{tabular}

BMI - body mass index; IOTF - International Obesity Task Force; SD - standard deviation.
Table 3 Specificity (\%) of BMI values proposed as limits for overweight and obesity by Cole et al. (IOTF) ${ }^{16}$ and Must et al. ${ }^{7,8}$, compared with weight-for-height index and Z-score $>2 S D$ as cut-off point, for schoolchildren

\begin{tabular}{|c|c|c|c|c|c|c|}
\hline & \multicolumn{2}{|c|}{ Males } & \multicolumn{2}{|c|}{ Females } & \multicolumn{2}{|c|}{ Both } \\
\hline & Cole & Must & Cole & Must & Cole & Must \\
\hline Ove & 92.9 & 80. & 92 & 79. & 92.9 & 80.1 \\
\hline Obesity & 100.0 & 99.5 & 99.6 & 98.2 & 99.8 & 98.9 \\
\hline
\end{tabular}

BMI - body mass index; IOTF - International Obesity Task Force; SD - standard deviation.

Table 4 Agreement between nutritional classification by BMI values proposed as limits for overweight and obesity by Cole et al. (IOTF) ${ }^{16}$ and Must et al. ${ }^{7,8}$ and weight-for-height index and $Z$-score $>$ 2SD as cut-off point, measured by kappa index, for schoolchildren

\begin{tabular}{lllllllll}
\hline & \multicolumn{2}{c}{ Males } & & \multicolumn{2}{c}{ Females } & & \multicolumn{2}{c}{ Both } \\
\cline { 2 - 3 } & Cole & Must & & Cole & Must & & Cole & Must \\
\hline Overweight & 0.66 & 0.63 & & 0.47 & 0.47 & & 0.56 & 0.55 \\
Obesity & 0.48 & 0.69 & & 0.31 & 0.40 & & 0.38 & 0.53 \\
\hline
\end{tabular}

BMI - body mass index; IOTF - International Obesity Task Force; $\mathrm{SD}$ - standard deviation.

$\pm 2 \mathrm{SD}$ from the median as cut-off points because this defines the central $95 \%$ of the reference distribution as the 'normality' range. But the biological definition of what is or is not normal is complex, and the cut-off should distinguish a deficit that matters from one that is of no real significance $^{2}$. Any borderline point implies mistakes and involves sensitivity and specificity concepts. Since anthropometric data (weight and height) and its index have an almost Gaussian distribution, when the threshold chosen to limit eutrophy from nutritional disorders is closer to the central point of a normal distribution, sensitivity will be improved at the cost of specificity. When the opposite occurs, the threshold is far from the central point, and the specificity will be higher than the sensitivity ${ }^{22}$.

Since the increase in prevalence of obesity, especially in children, is a recent matter, the use of a $Z$-score of $+2 S D$ may not have any proven association with morbidity and mortality in childhood, adolescence or adulthood. On the other hand, the use of a $Z$-score of - 2SD of weight-forheight index has provided evidence of higher morbidity and mortality of children having a $Z$-score below this value $^{1}$.

But the use of weight-for-height index to screen for obesity in children has been used infrequently. The WHO recommendation of using Must et al.' $\mathrm{s}^{7,8}$ BMI values as a cut-off point to screen for overweight and obesity in adolescents has been extended to children.

Several other BMI curves have been proposed by different authors ${ }^{9-16}$ and have been used to screen obesity in children, which, as stated above, makes comparison of prevalences more difficult ${ }^{4}$ and establishing consensual criteria for the upper limit of normality in children and adolescents problematic ${ }^{18}$. 
Table 5 Sensitivity (\%), specificity (\%) and agreement of BMI values proposed as limits for overweight and obesity by Cole et al. (IOTF) ${ }^{16}$, compared with weight-for-height index and Z-score $>$ 2SD as cut-off point, for pre-school children

\begin{tabular}{lcccccccc}
\hline & \multicolumn{2}{c}{ Males } & & \multicolumn{2}{c}{ Females } & & \multicolumn{2}{c}{ Both } \\
\cline { 2 - 3 } & Overweight & Obesity & & Overweight & Obesity & & Overweight & Obesity \\
\hline Sensitivity & 97.6 & 81.7 & & 91.6 & 74.7 & & 94.4 & 77.9 \\
Specificity & 89.9 & 99.1 & & 89.9 & 99.4 & & 89.9 & 99.2 \\
Agreement $^{*}$ & 0.62 & 0.85 & & 0.61 & 0.81 & & 0.61 & 0.83 \\
\hline
\end{tabular}

BMI - body mass index; IOTF - International Obesity Task Force; SD - standard deviation.

${ }^{*}$ Kappa index.

Cole et al. (IOTF) ${ }^{16}$ were the first authors to present BMI cut-off values for children and adolescents, pointing out the recent tendency for basing BMI cut-off points on continuity with the definition of obesity in adulthood (which is based on statistical criteria of morbidity and mortality) to define obesity in childhood ${ }^{4,10,12,16,17}$. Their values have some more positive aspects than those of Must $e$ e $a l^{7,8}$ : they cover children from 2 to 6 years old; their values are presented for 6-month age intervals; and they are based on a bigger sample from six different countries.

For school-aged children Cole et al.'s (IOTF) ${ }^{16}$ values have a low sensitivity when compared with weight-forheight, which makes their use to screen obesity in children less useful since they could not detect more than $80 \%$ of those classified as obese by WHO recommendations (Table 2). Or, in other words, they have a chance of misclassifying as normal $20 \%$ of children who are obese according to $\mathrm{WHO}$ recommendations. The same statement is true about Must et al.' $\mathrm{s}^{7,8}$ values because the sensitivity of their BMI values is similar.

On the other hand, the values proposed as limits for obesity by Must et $a l^{7,8}$ and Cole et al. (IOTF) ${ }^{16}$ have a high specificity when compared to the weight-for-height index. This means that they have a very low chance of classifying eutrophic children as obese (false positives) (Table 3).

It should be considered that although WHO recommends the use of weight-for-height to identify obese children, this index is just another way of adjusting weight for height, as BMI does, and has no greater intrinsic validity than BMI for assessing obesity. In truth, the ideal gold standard method is a more direct measure of body fat such as dual-energy X-ray absorptiometry (DEXA), which is obviously more difficult to obtain. A recent study has shown that for children aged 2-19 years, compared with DEXA, the performance of BMI-for-age in predicting overweight is similar to that of weight-for-height ${ }^{25}$.

Since there is no agreement as to which anthropometric index, and cut-off value, should be considered as the gold standard, the three criteria studied in this paper were compared by the kappa index to measure the agreement between BMI values and weight-for-height index in classifying children as obese. A weak or reasonable concordance was found for the proposals of both authors, for all ages and sex. Specifically, for pre-school children, the concordance was found to be excellent for both authors (Table 4). The concordance on nutritional evaluation of children and adolescents of BMI values proposed by Cole et al. (IOTF) ${ }^{16}$ and Must et al.$^{7,8}$ was also demonstrated in another study as excellent ${ }^{26}$.

The sensitivity, specificity and agreement of BMI values proposed by Cole et al. (IOTF) ${ }^{16}$ with weight-for-height index are better for pre-school children than for schoolchildren. These statistics were not tested, for pre-school children, with Must et al.' s $^{7,8}$ values since these authors only cover children aged 6 years or older.

If the WHO definition of obesity in childhood continues to be recommended (gold standard), it is concluded that the values proposed by Must et al. ${ }^{7,8}$ and Cole et al. (IOTF $)^{16}$ do not have high sensitivity compared to weightfor-height index and should be used carefully to screen obesity in childhood. Owing to their high specificity, the values proposed as limits for obesity by both authors can be used to 'diagnose' overweight children with a very low chance of giving false-positive results. This is particularly important in young, rapidly growing children to avoid incorrect and detrimental food restriction. Although the performance of Cole et al.'s (IOTF) and Must et al.'s values was similar, based on kappa results, the use of Cole et al.'s (IOTF) proposals should be encouraged because they have some more positive aspects. They cover children from 2 to 6 years of age; their values are presented for 6-month age intervals; and they are based on a larger sample from six different countries. The most positive aspect of using BMI values proposed by Cole et al. (IOTF) is that they are easier to cope with and understand than $Z$ score values.

It should be emphasised that 'the use and interpretation of growth measurements may differ significantly according to whether they concern the individual (for clinical purposes) or an entire population (for public health purposes $)^{1}$. The difference in obesity prevalence described with the use of different obesity definitions ${ }^{24,25}$ is a very serious problem because some individuals will be misclassified as normal or obese and will not receive intervention appropriate to their nutritional status. These differences in individual subject classifications are 
important for future studies that seek to determine whether certain chosen cut-off limits are linked with morbidity and mortality endpoints, which relies on values for individuals, since none of these three methods has been demonstrated to predict outcome. There is an urgent necessity to establish consensual criteria for obesity definition in childhood that would predict morbidity and mortality in adulthood.

\section{References}

1 World Health Organization (WHO). Physical Status: The Use and Interpretation of Anthropometry. Geneva: WHO, 1995.

2 World Health Organization Working Group. Use and interpretation of anthropometric indicators of nutritional status. Bull. World Health Org. 1986; 64: 929-41.

3 Quetelet A. Physique sociale: ou, essai sur le développement des facultés de l'homme. Brussels, Belgium: C. Muquardt, 1869.

4 Bellizzi MC, Dietz WH. Workshop on childhood obesity: summary of the discussion. Am. J. Clin. Nutr. 1999; 70: S173-5.

5 Willet WC, Dietz WH, Colditz GA. Guidelines for healthy weight. New Engl. J. Med. 1999; 341: 427-34.

6 Stevens J. Impact of age on associations between weight and mortality. Nutr. Rev. 2000; 58: 129-37.

7 Must A, Dallal GE, Dietz WH. Reference data for obesity: 85th and 95th percentiles of body mass index (wt/ht $\left.{ }^{2}\right)$ and triceps skinfold thickness. Am. J. Clin. Nutr. 1991; 53: 839-46.

8 Must A, Dallal GE, Dietz WH. Reference data for obesity: 85th and 95th percentiles of body mass index $\left(\mathrm{wt} / \mathrm{ht}^{2}\right)$ and triceps skinfold thickness - a correction. Am.J. Clin. Nutr. 1991; 54: 773 .

9 Roberts SB, Dallal GE. The new childhood growth charts. Nutr. Rev. 2001; 59: 31-6.

10 Cole TJ, Freeman JV, Preece MA. Body mass index reference curves for the UK, 1990. Arch. Dis. Child. 1995; 73: 25-9.

11 Lindgren G, Strandell A, Cole T, Healy M, Tanner J. Swedish population reference standards for height, weight and body mass index attained at 6 to 16 years (girls) or 19 years (boys). Acta Paediatr. 1995; 84: 1019-28.

12 Sichieri R, Allam VLC. Avaliação do estado nutricional de adolescentes brasileiros através do índice de massa corporal J. Pediatr. (Rio de Janeiro) 1996; 72: 80-4.

13 Luciano A, Bressan F, Zoppi G. Body mass index reference curves for children aged 3-19 years from Verona, Italy. Eur. J. Clin. Nutr. 1997; 51: 6-10.

14 Rosner B, Prineas R, Loggie J, Daniels SR. Percentiles for body mass index in US children 5 to 17 years of age. J. Pediatr. 1998; 132: 211-21.

15 Anjos LA, Veiga GV, Castro IRR. Distribuição dos valores do índice de massa corporal da população brasileira até 25 anos. Rev. Panam. Salud Publica/Am. J. Public Health 1998; 36 : 3-7.

16 Cole TJ, Bellizzi MC, Flegal KM, Dietz WH. Establishing a standard definition for child overweight and obesity worldwide: international survey. Br. Med. J. 2000; 320: $1-6$.

17 Himes LH, Dietz WH. Guidelines for overweight in adolescent preventive services: recommendations from an expert committee. Am. J. Clin. Nutr. 1994; 150: 307-16.

18 Dietz WH, Robinson TN. Use of body mass index (BMI) as a measure of overweight in children and adolescents [Editorial]. J. Pediatr. 1998; 132: 191-3.

19 Kain J, Uauy R, Vio F, Albala C. Trends in overweight and obesity prevalence in Chilean children: comparison of three definitions. Eur. J. Clin. Nutr. 2002; 56: 200-4.

20 Flegal KM, Ogden CL, Wei R, Kuczmarski RL, Johnson CL. Prevalence of overweight in US children: comparison of US growth charts from the Centers for Disease Control and Prevention with other reference values for body mass index. Am.J. Clin. Nutr. 2001; 73(6): 1086-93.

21 Ministério do Planejamento, Orçamento e Gestão. Pesquisa sobre Padrões de Vida 1996-1997. Rio de Janeiro: Brazilian Institute of Geography and Statistics, 1999.

22 Dean AG, Dean JA, Coloumbier D, Burton AH, Brendei KA, Smith DC. Epi Info, Version 6.04: A Word Processing, Database, and Statistics Program for Public Health on Microcomputers. Atlanta, GA: Centers for Disease Control and Prevention/World Health Organization, 1996.

23 Agresti A. Categorical Data Analysis. New York: Wiley Interscience, 1990.

24 Mausner JS, Kramer S. Epidemiology - An Introductory Text. Philadelphia, PA: Saunders Company, 1985.

25 Mei Z, Grummer-Strawn LM, Pietrobelli A, Goulding A, Goran MI, Dietz WH. Validity of body mass index compared with other body-composition screening indexes for the assessment of body fatness in children and adolescents. Am. J. Clin. Nutr. 2002; 75: 978-85.

26 Abrantes MM, Lamounier JA, Colosimo EA. Recommendations for the use of body mass index for the classification of overweight and obese children and adolescents. Food Nutr. Bull. 2002; 23(3): 262-6. 